\title{
Incidentally detected large idiopathic brachial artery aneurysm: a potentially life-threatening discovery
}

\author{
Apurva Vasavada, Navin Agrawal, Pritesh Parekh, Mahesh Vinchurkar
}

Department of Cardiovascular Sciences, Care Hospital, Surat, Gujarat, India

\section{Correspondence to} Dr Navin Agrawal, drnavinagrawal@gmail.com

Accepted 30 December 2014
CrossMark

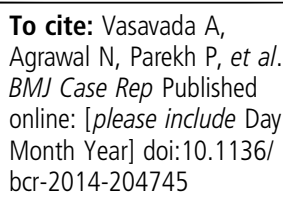

\section{DESCRIPTION}

While peripheral artery aneurysms are rarely encountered, brachial artery aneurysms are even rarer. Most of those seen are usually dissecting aneurysms of infectious, post-traumatic or iatrogenic origin; true aneurysms of the brachial artery are even more unusual. ${ }^{12}$ There may be a cause of in situ thrombosis, which might occlude vessels. The risk of limb loss can be avoided by prompt diagnosis and early surgery. ${ }^{3}{ }^{4}$ The best therapeutic option is operative repair or closure by covered stent, although there are no uniform guidelines regarding the timing and indications of intervention.

We present an interesting case of a 58-year-old man who presented with symptoms of atypical chest pain with non-specific ST-T changes in the ECG. The patient was taken up for a diagnostic angiogram from the right radial access but difficulty was experienced in negotiating the wire across the brachial artery. The wire took an unusual loop in the brachial artery (figure 1 and video 1); the check shot taken showed a large brachial artery aneurysm (figures 2 and 3, videos 2 and 3). The coronary angiogram subsequently performed revealed insignificant coronary artery disease.

The patient was planned for conservative management for the coronary artery disease and since the aneurysm was incidentally detected, the patient was given the option of surgical correction or percutaneous treatment with covered stent. The patient opted for conservative management.

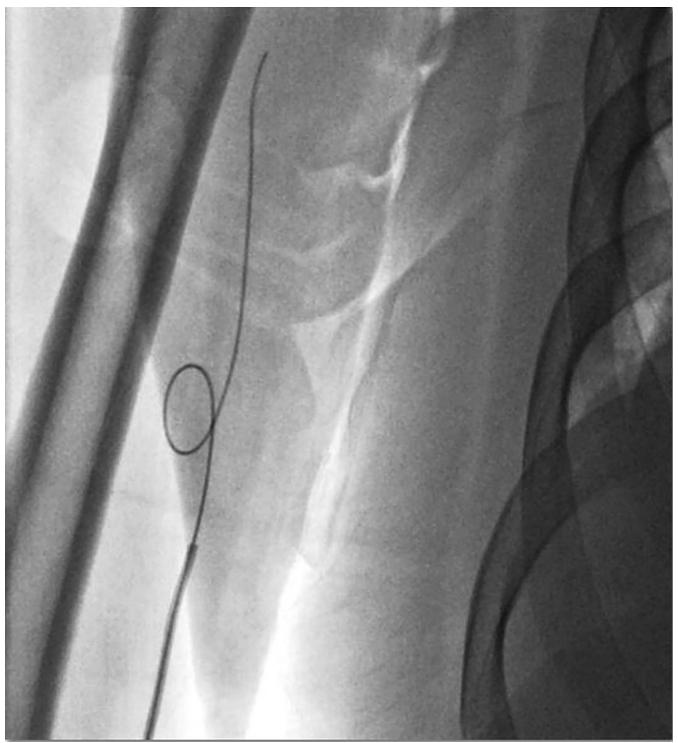

Figure 1 Loop formed by the terumo wire used to cross the catheter for a diagnostic coronary angiogram performed from the right radial route.

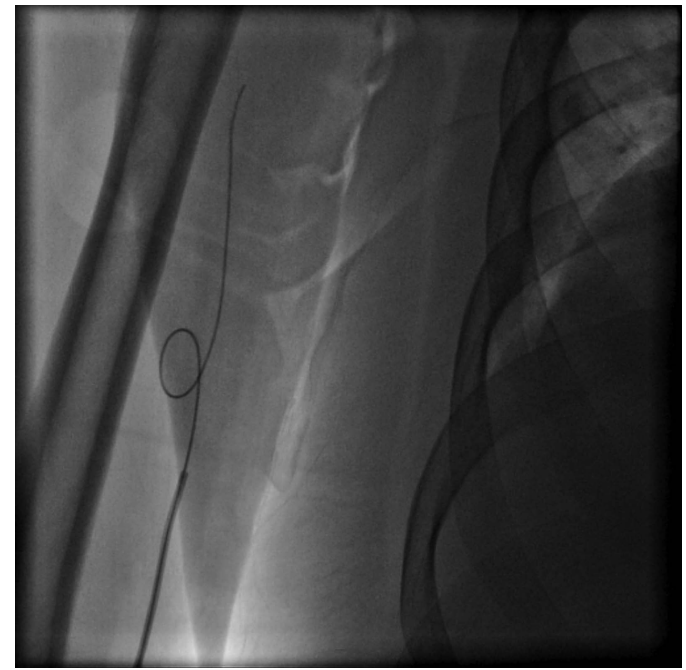

Video 1 Loop formed by the terumo wire used to cross the catheter for a diagnostic coronary angiogram performed from the right radial route.

The patient was asymptomatic at 3 months of follow-up.

The aetiopathogenesis of aneurysms is multifactorial with a definite role of genetic predisposition working hand in hand with risk factors that are mostly similar to those for atherosclerosis, such as smoking, hypertension and dyslipidaemia, in association with others such as copper deficiency and tertiary syphilis. ${ }^{5}$ This patient had none of these risk factors and no family history of aneurysms or coronary artery diseases. The coronary arteries had

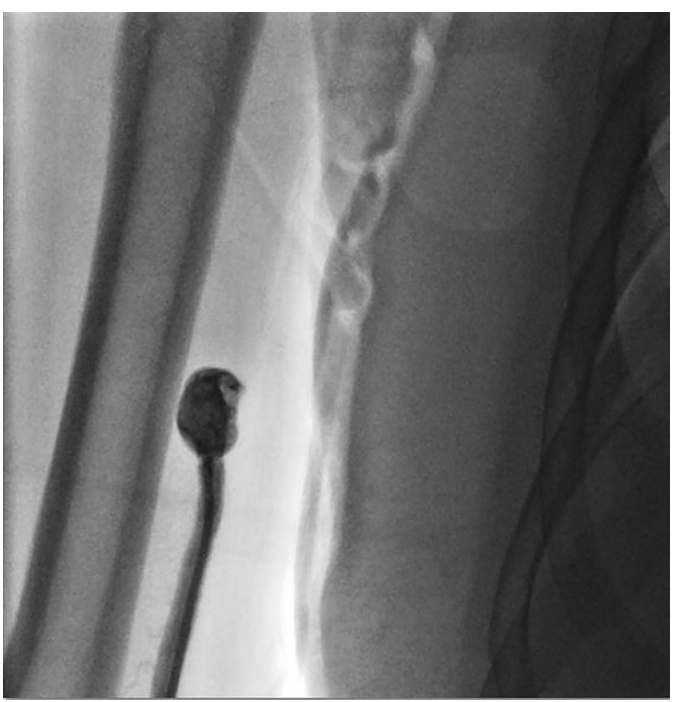

Figure 2 The brachial artery aneurysm opacified by contrast shot antegradely by a $5 \mathrm{~F}$ Tiger catheter. 


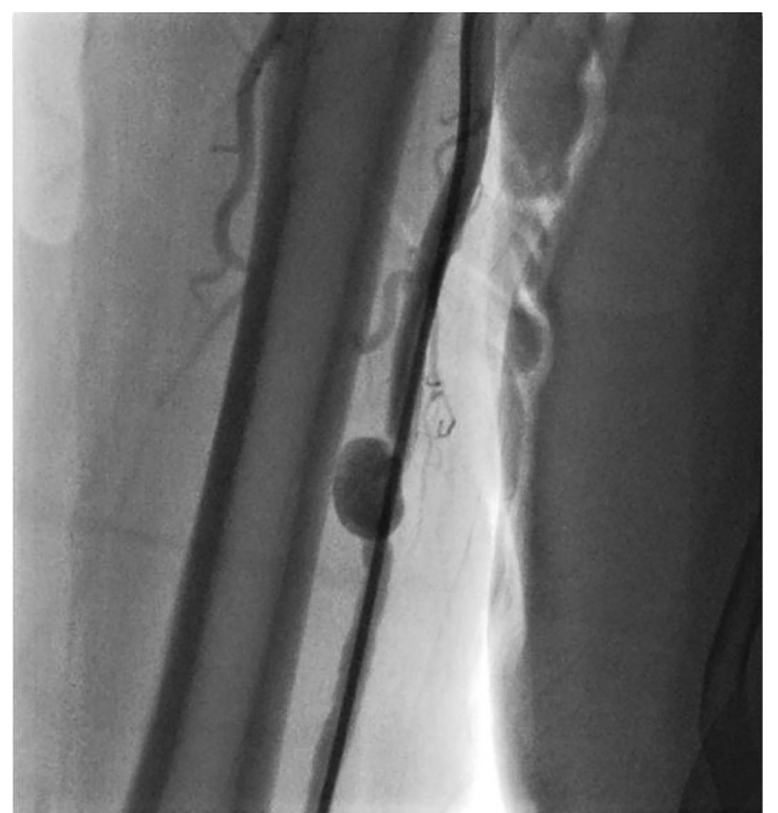

Figure 3 Retrograde shot taken while removing the catheter after the coronary angiogram showing the large brachial artery aneurysm.

evidence of mild atherosclerosis, which might have played a part in this.

Prevention of aneurysm formation and enlargement includes control of risk factors, while drugs such as $\beta$-blockers and losar$\tan$ have shown some benefit. ${ }^{6}{ }^{7}$ There are no clear guidelines for the management of incidentally detected and asymptomatic peripheral artery aneurysm in contrast to aortic aneurysm.

For most cases of giant aneurysms, surgical therapy forms the standard of care, although in appropriately selected cases covered stent is a reasonable alternative. There have been a series of successes of covered stents in peripheral aneurysms but higher incidence of stent thrombosis has been reported. ${ }^{8}$

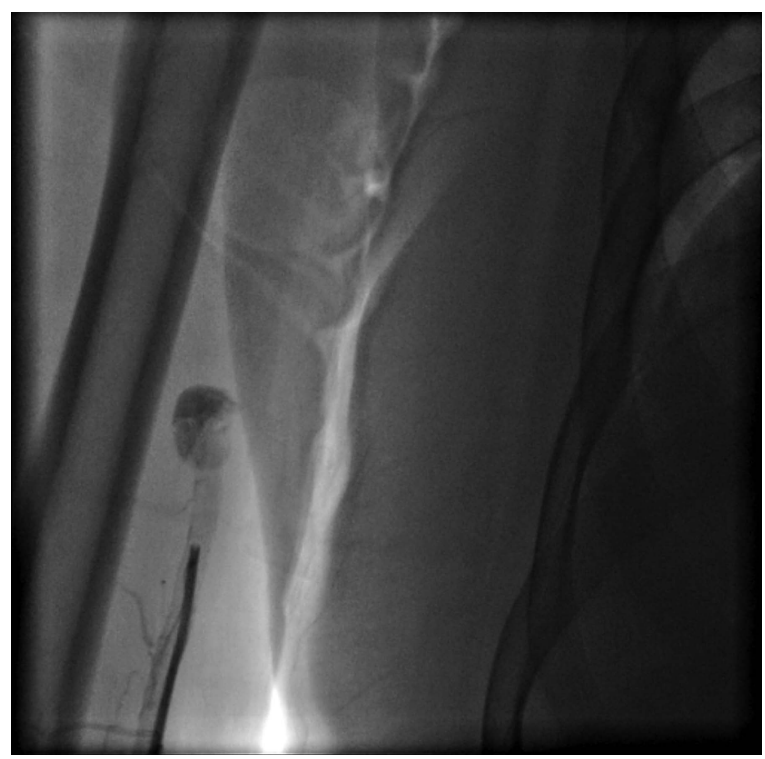

Video 2 The brachial artery aneurysm opacified by contrast shot antegradely by a $5 \mathrm{~F}$ Tiger catheter.

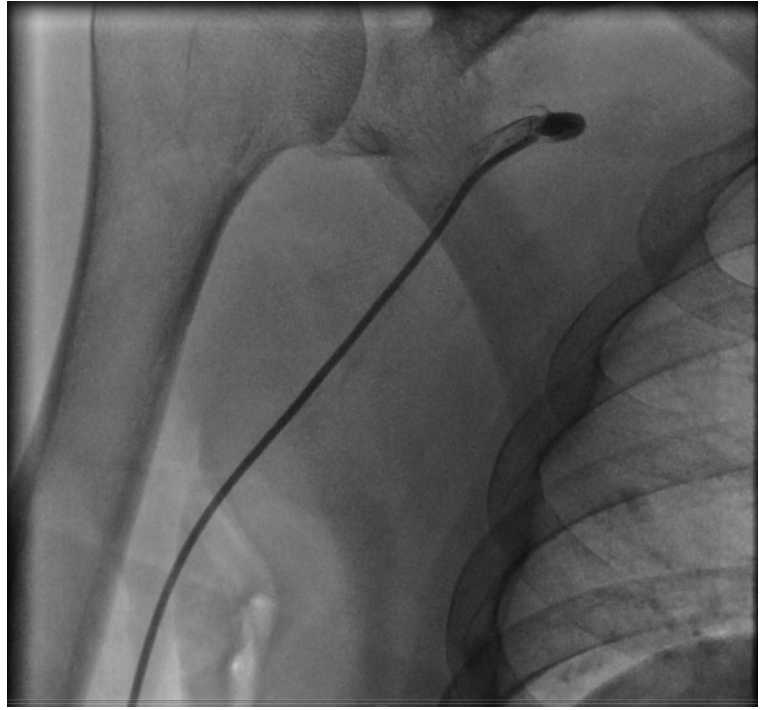

Video 3 Retrograde shot taken while removing the catheter after the coronary angiogram showing the large brachial artery aneurysm.

\section{Learning points}

- Peripheral artery aneurysms are rare and usually found incidentally. They may be observed clinically in the form of unusual pulsations or as an abnormal pulsatile swelling. Rarely, the first presenting symptom could be pain, thrombosis or acute rupture. Idiopathic aneurysms are rarely seen.

- There are no specific guidelines for their management and no clear cut-off size or symptom level for an intervention to be undertaken.

- Corrective surgery or percutaneous closure using covered stents are acceptable treatment options in management of such cases. Long-term follow-up and the incidence of recurrence may be variable with respect to the aetiology and success of correction.

\section{Competing interests None.}

Patient consent Obtained.

Provenance and peer review Not commissioned; externally peer reviewed.

\section{REFERENCES}

1 Bahcivan M, Yuksel A. Idiopathic true brachial artery aneurysm in a nine-month infant. Interact Cardiovasc Thorac Surg 2009;8:162-3.

2 Schunn CD, Sullivan TM. Brachial arteriomegaly and true aneurysmal degeneration: case report and literature review. Vasc Med 2002;7:25-7.

3 Fann JI, Wyatt J, Frazier RL, et al. Symptomatic brachial artery aneurysm in a child. J Pediatr Surg 1994;29:1521-3.

4 Tetik 0, Ozcem B, Calli AO, et al. True brachial artery aneurysm. Tex Heart Inst J 2010;37:618-19.

5 Colledge NR, Walker BR, Ralston S. Davidson's principles and practice of medicine. 21st edn. Edinburgh: Churchill Livingstone/Elsevier. 2010:604. ISBN 978-0-70203085-7.

6 Chakkour K, Gouny P, Nussaume 0, et al. Medical treatment of aortic aneurysms using beta-blockers. J Mal Vasc 1995;20:288-9.

7 Groenink $M$, den Hartog AW, Franken $R$, et al. Losartan reduces aortic dilatation rate in adults with Marfan syndrome: a randomized controlled trial. Eur Heart $J$ 2013;34:3491-500.

8 Beregi JP, Prat A, Willoteaux $S$, et al. Covered stents in the treatment of peripheral arterial aneurysms: procedural results and midterm follow-up. Cardiovasc Intervent Radiol 1999;22:13-19. 
Copyright 2015 BMJ Publishing Group. All rights reserved. For permission to reuse any of this content visit http://group.bmj.com/group/rights-licensing/permissions.

BMJ Case Report Fellows may re-use this article for personal use and teaching without any further permission.

Become a Fellow of BMJ Case Reports today and you can:

- Submit as many cases as you like

- Enjoy fast sympathetic peer review and rapid publication of accepted articles

- Access all the published articles

- Re-use any of the published material for personal use and teaching without further permission

For information on Institutional Fellowships contact consortiasales@bmjgroup.com

Visit casereports.bmj.com for more articles like this and to become a Fellow 